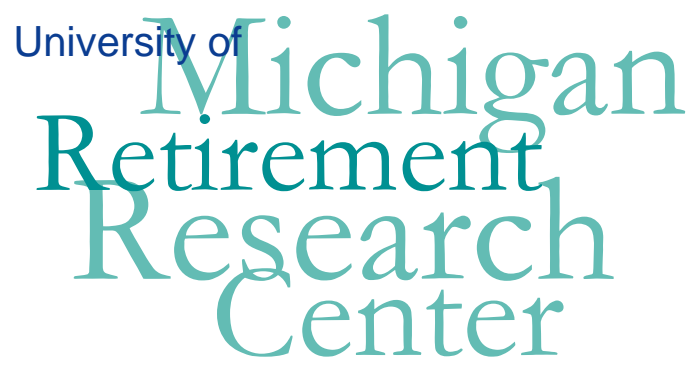

Working Paper

WP 2009-213

Gain and Loss: Marriage and Wealth Changes Over Time

Julie M. Zissimopoulos

\begin{tabular}{|l|l|l|l|l|l|l}
\hline $\mathrm{M}$ & $\mathrm{R}$ & Project \#: UM09-19 \\
\hline $\mathrm{R}$ & $\mathrm{C}$ & \\
\hline
\end{tabular} 



\title{
Gain and Loss: Marriage and Wealth Changes Over Time
}

\author{
Julie M. Zissimopoulos \\ RAND
}

September 2009

\author{
Michigan Retirement Research Center \\ University of Michigan \\ P.O. Box 1248 \\ Ann Arbor, MI 48104 \\ http://www.mrrc.isr.umich.edu/ \\ (734) 615-0422
}

\section{Acknowledgements}

This work was supported by a grant from the Social Security Administration through the Michigan Retirement Research Center (Grant \# 10-M-98362-5-01). The findings and conclusions expressed are solely those of the author and do not represent the views of the Social Security Administration, any agency of the Federal government, or the Michigan Retirement Research Center.

\section{Regents of the University of Michigan}

Julia Donovan Darrow, Ann Arbor; Laurence B. Deitch, Bingham Farms; Denise Ilitch, Bingham Farms; Olivia P. Maynard, Goodrich; Andrea Fischer Newman, Ann Arbor; Andrew C. Richner, Grosse Pointe Park; S. Martin Taylor, Gross Pointe Farms; Katherine E. White, Ann Arbor; Mary Sue Coleman, ex officio 


\title{
Gain and Loss: Marriage and Wealth Changes Over Time
}

\begin{abstract}
Family composition has changed dramatically over the past 25 years. Divorce rates increased and remarriage rates declined. While considerable research established a link between marriage and earnings, far less is empirically understood about the effect of marriage on wealth although wealth is an important measure for older individuals because it represents resources available for consumption in retirement. In this paper we employ eight waves of panel data from the Health and Retirement Study to study the relationship between wealth changes and marital status among individuals over age 50. This research advances understanding of the relationship by first, incorporating measures of current and lifetime earnings, mortality risk and other characteristics that vary by marital status into models of wealth change; second, measuring the magnitude of wealth loss and gain associated with divorce, widowing and remarriage and third, estimating wealth change before and after marital status change so the change in wealth change is not the result of individuals entering or leaving the household and other sources of unobserved differences are removed from estimates of the effect of marriage on wealth. Our results suggest no differences in wealth change over time among individuals that remain married, divorced, widowed, never married and partnered over 7 years. In the short-run there are substantial wealth changes associated with marital status changes. Divorce at older ages is costly, remarriage is wealth enhancing and people appear to change their savings in response to changes in marital status.
\end{abstract}

\section{Authors’ Acknowledgements}

I thank Joanna Carroll for her excellent programming assistance. 


\section{Introduction}

Family composition has changed dramatically over the past 25 years. Divorce rates rapidly increased from the late 1960's through the 1980's and remarriage rates have declined (Cherlin 1992). Considerable research has established a correlation between marital status and socio-economic status, particularly a positive relationship between marriage and male earnings (Korenman and Neumark 1991; Lundberg and Rose 2002; Loughran and Zissimopoulos 2009). Considerably less attention has been paid to the effect of marriage on women's earnings because of the strong correlation of marriage and childbearing. One exception is Loughran and Zissimopoulos (2009) and they find marriage lowers female wages the year of marriage and wage growth in subsequent years. While income is a critical measure of well being, wealth is an important complementary measure and arguably the most important measure for older individuals because it represents resources available for consumption in retirement. Far less is empirically understood about the effect of marriage on wealth compared to the effect of marriage on earnings although theory suggests it is likely to be important.

An important implication of economic models of savings with no uncertainty (or agents maximize expected utility) and perfect capital markets is that consumption is determined by permanent income. This implies that changes in permanent income are consumed and temporary changes are saved. Relaxing these assumptions provides a role for both permanent and transitory income in consumption and savings decisions. Changes in marital status that affect permanent income will change consumption levels. Moreover, changes in marital status will affect wealth depending on whether the change is considered transitory or permanent. For example, the behavioral response to a 
separation or divorce expected to be temporary may be to lower savings to avoid a drop in consumption. Lupton and Smith (2002) find dissaving is most common the shorter the duration in the non-marriage state as households attempt to maintain prior consumption levels. Consumption and savings behavior may change prior to the event. For example, Zagorsky (2005) found that savings declines begin prior to divorce.

Other hypotheses regarding the effect of marriage on wealth include economies of scale (Waite 1995), mortality risk (Lillard and Weiss 1996), children and inter-vivos transfers and bequests (Hurd, Smith, Zissimopoulos 2006), precautionary savings (Mincer 1978) and retirement planning. Married couples may consume many goods and services jointly (entertainment, housing) for the same cost as a single person. These economies of scale may translate into additional wealth or additional consumption. Marriage may produce better health, thus married couples will save more to protect against outliving their resources. On the other hand, marriage reduces risk associated with fluctuations in income and thus may lower precautionary savings against income shocks or other shocks. ${ }^{1}$ In sum, there are many pathways through which marriage and wealth are associated. Moreover, the consistent empirical finding of a relationship between marriage and wealth suggests its importance as an area for further study. Yet, challenging estimation of the empirical relationship between marriage and wealth is the non-random sorting of individuals into marriage. For example, low-income families are more likely to divorce or experience widowhood than high-income families. Prior empirical studies have been hindered by a lack of control measures for permanent income

\footnotetext{
${ }^{1}$ Children are one important reason for marriage and their presence may either increase savings (to leave as a bequest) or decrease savings because of the additional consumption associated with children.
} 
and by use of cross-sectional surveys and short panels that are ill-suited for distinguishing between selection and behavioral response.

In this paper we employ eight waves of panel data from the Health and Retirement Study to study the relationship between wealth changes and marital status among individuals over age 50. This research advances understanding of the relationship by first, incorporating measures of current and lifetime earnings, mortality risk and other characteristics that vary by marital status into models of wealth change; second, measuring the magnitude of wealth loss and gain associated with divorce, widowing and remarriage and third, estimating wealth change before and after marital status change so the change in wealth change is not the result of individuals entering or leaving the household and other sources of unobserved differences are removed from estimates of the effect of marital status on wealth. The remainder of this paper has the following structure. The next section summarizes describes the data and derivation of key variables. Section 3 presents main results for wealth levels and changes and for individuals that do and do not change marital status. The final section concludes.

\section{Data}

The research relies on longitudinal data from the Health and Retirement Study, a set of biennial surveys first fielded in 1992 and 1993 by the University of Michigan with the objective to monitor economic transitions in work, income and wealth, and changes in health among those over 50 years old. ${ }^{2}$ We use data from survey waves 1992, 1993, 1994, 1995, 1996 and biennial thereafter to $2006 .^{3}$

\footnotetext{
2 The first survey, the Health and Retirement Study (HRS) began as a national sample of about 7,600 households $(12,654$ individuals) with at least one person in the birth cohorts of 1931 through 1941 (about
} 
We use data including all cohorts with the exception of the 1948 to 1953 birth cohort added in year 2004 for which insufficient waves of data for this analysis have been collected. In addition, we use restricted data on Social Security earnings to compute a measure of lifetime earnings. Marital history variables (all prior marriages, divorces and widowings) were derived based on the raw HRS files; most other variables used in the study are from the RAND HRS Data file, Version $I^{4}$. Further details on key analytic variables follow.

Marital Status. Respondents are categorized at a point in time as being either married, divorced, widowed, partnered or never married. For some analyses we use respondents' reports of past marital events to distinguish between married and remarried individuals. Changes over the panel are based on respondents' report of any changes between waves and we group them into six categories: separated to divorced, married to divorced, married to widowed, divorced to married, widowed to married, other single (partnered or never married) to married.

Lifetime Earnings. We calculate lifetime earnings based on historical earnings reported to the Social Security Administration. We use earnings from 1951 to 1991 for 9,539 HRS respondents. ${ }^{5}$ Earnings data for the War Babies cohort are available for 1,330

51-61 years old at the wave 1 interview in 1992). The second, the Assets and Health Dynamics of the Oldest Old (AHEAD), began in 1993 and included 6,052 households (8,222 individuals) with at least one person born in 1923 or earlier (70 or over in 1993). In 1998, HRS was augmented with baseline interviews from at least one household member from the birth cohorts 1924-1930 and 1942-1947 and was representative of all birth cohorts born in 1947 or earlier. In 2004, the HRS was again augmented with interviews from the birth cohort 1948-1953.

${ }^{3}$ For the original HRS respondents from survey wave 1992, we use a total of 8 waves of data from 1992 to 2006. For the original AHEAD respondents from 1993, we have 7 waves of data. For respondents added in 1998, we have 5 survey waves from 1998 to 2006.

${ }^{4}$ RAND HRS is a longitudinal data set based on the HRS data and developed at RAND with funding from the National Institute on Aging and the Social Security Administration.

${ }^{5}$ See Haider and Solon (2000) for a discussion of characteristics of individuals with and without matched Social Security records. 
respondents for years 1951 to 1997 . The administrative records are accurate and less subject to measurement error than self-reported earnings from household surveys and cover a long history of earnings. They are however, limited in two ways. First, the level of earnings is reported only up to the Social Security maximum. This maximum changed over time as did the number of individuals whose earnings were above the maximum. Second, individuals employed in a sector not covered by Social Security have no earnings records for the years he or she is employed in the uncovered sector. ${ }^{6}$ Lifetime earnings are calculated as the present discounted value ( 3 percent real interest rate) of real Social Security earnings adjusted to 2006 dollars using the CPI-U-RS, and we adjust for the upper truncation of Social Security earnings.

Mortality Risk, Risk Aversion, Time Rate of Preference. Mortality risk is the respondent's subjective survival assessment of living to age $75(85)$ on a zero to 100 scale and we include it in empirical models as the deviation from lifetables based on sex and age. The basis for categorizing the level of risk aversion is a series of questions that ask respondents to choose between pairs of jobs where one job guarantees current family income and the other offers the chance to increase income and carries the risk of loss of income. From responses to these questions we categorize a respondent's level of risk aversion into four groups. We measure respondents' time rate of preference by their responses to the length of time they use for financial planning. The answers are categorical from a few months to over ten or more years.

Wealth. Our main outcome measures are wealth, change in wealth and the change in the change in wealth. Wealth is housing plus non-housing wealth and is computed as the sum of wealth from real estate, businesses, IRAs, stocks, bonds, checking accounts,

\footnotetext{
${ }^{6}$ In 1996, 92\% of non-self-employed wage and salary workers were covered by Social Security.
} 
CDs, and housing, less the value of the mortgage, home loans, and other debt. Missing data on wealth are imputed and the methods are described in RAND HRS Version I. Some analysis use information on a respondent's pension ownership and type (defined benefit, defined contribution, both).

\section{Results}

Changes in marital status occur over the lifespan, even at older ages. We examine current marital status and future changes in marital status over the next 14 years and present their distribution in Table 1. Among the birth cohort 1931-1941, 84 percent are married in 1992, 10 percent are divorced and 6 percent are widowed. Over the next 14 years, 15 percent of this sample of respondents, on average 55 years old, change marital status. About 4 percent of married respondents divorce and 10 percent are widowed. Just over one percent of individuals divorced or widowed remarries over this time period.

The level of wealth held in 1992 by this birth cohort varies with current marital status as well as future changes in marital status. The first three rows in Table 2 are groups that, as of 1992, have not experienced a marital disruption. The data in Table 2 shows respondents that are married in 1992 and have no marital status changes over the next 14 years have higher mean and median wealth than married respondents that will eventually divorce or be widowed. This group of continuously married individuals has on average $\$ 363,814$ in housing and non-housing wealth (not including pension wealth) compared to $\$ 278,365$ for married respondents that will divorce and compared to $\$ 254,362$ for married respondents that will be widowed. Age differences by group are small and thus unlikely to account for the mean and median differences. Remarried 
individuals that remain married through the 14 years have lower average wealth $(\$ 281,843)$ than married individuals who remain married over the panel, and at the mean and median, only marginally higher than those married that will go on to divorce or be widowed. All not married individuals have lower mean wealth than married individuals although at the median, not married individuals who remarry in panel have higher median wealth than some married individuals. Among the not married groups, mean wealth of divorced $(\$ 116,572)$ and widowed $(\$ 125,835)$ individuals that remain not married is about $60 \%$ of the wealth that not married individuals that go on to remarry have (\$188,366 and $\$ 199,769$ respectively for divorced then remarried and widowed and then remarried).

The wealth differences at about age 55 by current marital status and future changes may be a result of wealth loss due to marital disruption or observable differences in for example, earnings or preferences for savings. For example, marital groups may save at similar rates but save out of lower levels of income. Table 2 also shows lifetime earnings, current earnings and the ratio of wealth to lifetime earnings. Comparing individuals that are married and stay married with those that are married and go on to divorce, Table 2 shows that lifetime earnings and current earnings are similar and thus differences in earnings over the life-cycle is unlikely to account for the wealth differences. Remarried individuals that stay remarried have slightly higher lifetime earnings, same current earnings and yet, their mean wealth is 77 percent of the wealth of individuals that are married (not remarried) and stay married over the panel. This is pattern is consistent with wealth loss due to marital disruption. Not married individuals have lower wealth than married individuals and indeed, their lifetime and current 
earnings are lower than married individuals. In sum, these data in Table 2 emphasize the role of lifetime earnings, the role of selection on characteristics other than income and the role of wealth loss due to marital dissolution in explaining wealth level differences by marital status.

\section{Changes in wealth among individuals with stable marital status.}

The magnitude of wealth change over time among individuals that change marital status will be dominated by wealth change due to individuals leaving or entering the household. Thus we first examine wealth changes over two years (all data waves $(\mathrm{t})$ and $(t+1))$ for individuals that do not change marital status over that same time period and results are shown in Table $3 .^{7}$ Wealth increases over two years for all groups. Married and remarried individuals have larger wealth changes than divorced, widowed, never married and partnered individuals. Compared to all other individuals wealth change is higher for married individuals by the following amounts: $\$ 3,222$ compared to remarried, $\$ 10,142$ compared to divorced, $\$ 17,317$ compared to widowed, $\$ 11,627$ compared to never married and $\$ 17,115$ compared to partnered. Wealth change as a percent of initial wealth level is slightly higher for divorced individuals ( 9 percent) than married, remarried and never married (7 percent). Wealth change as a percent of initial wealth level is 3 percent among widowed and partnered individuals. Thus, overall levels of wealth change are highest for married individuals but rates are similar compared to divorced and never married individuals.

\footnotetext{
${ }^{7}$ We trim the top and bottom 2 percent of wealth change values.
} 
We examine two-year wealth change by marital status controlling for basic demographic differences in sex, race and age and including year indicators. Results from the linear, multivariate model are reported in the first column of results in Table 4 (Model 1). The second column of results in Table 4 (Model 2) are estimates of the marginal effects of marital status on wealth change over two-years from a model that along with basic demographics, includes in the specification many other covariates including lifetime earnings (a measure of permanent income), current earnings, education, number of children, ownership of pension wealth and type of pension, mortality risk, risk aversion, and financial planning horizon. The marginal effects for all covariates are given in Appendix Table A. The results from Model 1 show remarried and all not married individuals have lower levels of wealth change over two years and the magnitude of difference is similar to the difference in Table 3. The inclusion of the additional covariates (Model 2) explains all of the difference in wealth change between married and remarried individual. The covariates reduce the difference in wealth change between married and remarried in Model 1 and Model 2 by \$1,192 (27 percent) and the difference is no longer statistically significant. The additional covariates in Model 2 explain about $50 \%$ of the wealth change difference between married and either divorced or widowed individuals. That is, the marginal effect is reduced from $\$-9,792$ in Model 1 to $\$-5,146$ in Model 2 for divorced individuals and from \$-15,886 to \$-7,922 for widowed individuals. The additional covariates in Model 2 explain about $30 \%$ of the wealth change difference between married and either never married or partnered individuals. Overall, measures of socio-economic status (lifetime and current earnings, education), pensions, and mortality 
risk explain between 30 and 50 percent of the difference in wealth between married and not married individuals.

Table 5 presents results for the effect of marital status on wealth change separately for samples of men and women. For men, demographic characteristics (included in Model 1) explain all of the difference in wealth change between married, remarried and not married men with the exception of partnered men. The inclusion of the additional covariates in Model 2 explains about 30 percent of the difference between married men and partnered men. For women, wealth change is lower for remarried and all not married women compared to married women with the exception of never married women. The inclusion of the additional covariates in Model 2 explains all of the difference between married and remarried or never married women, 40 percent of the difference between married and divorced women, 49 percent of the difference between married and widowed women and 30 percent of the difference between partnered and married women.

In sum, basic demographics explain all of the difference in wealth change by marital status for men (exception is partnered men), but not so for women. For women, the inclusion of additional controls for socio-economic status and other household and individual characteristics explains all of the difference between married and remarried women and between one third and one half of the difference between married women and other not married women. Thus for women, some of the variation is left unexplained.

\section{Changes in wealth among individuals that change marital status.}


To study wealth change in panel among individuals that change marital status, we examine wealth levels and changes in the two waves prior to the marital status change (t1 and $t)$, the two years over which the marital status change occurred ( $t$ and $t+1)$ and the two years after the marital status change occurred $(t+1$ and $t+2)$. Thus we limit our sample to individuals in four consecutive waves of data and exclude individuals with more than one marital change between survey waves. ${ }^{8}$ We also study wealth changes over the same time periods for individuals that do not change marital status. Results on wealth levels and changes are given in Table 6a and wealth changes as a percentage of the prior wave wealth level in Table $6 \mathrm{~b}$.

Among married and separated individuals that divorce between waves, wealth is already declining in the wave prior to the divorce (Table 6a). Married individuals that are divorced in time $\mathrm{t}+1$ experienced a $\$ 39,918$ wealth loss while married from time ( $\mathrm{t}-1$ ) to $(t)$, or 14 percent of their time (t-1) wealth (Table 6b). Over the two years in which the divorced occurred, married individuals lost another $\$ 132,779$ in wealth or about 53 percent of their time ( $t$ ) wealth. There is some wealth recovery after the divorce: wealth increased by $\$ 22,210$ or 19 percent. The dissaving before the divorce and savings after the divorce lead to a wealth change of $\$ 62,128$ from before $((t-1)$ to $(\mathrm{t}))$, to after $((\mathrm{t}+2)$ $(\mathrm{t}+1))$ the divorce. Separated individuals have wealth declines of $\$ 42,858$ over the two years they are separated $((\mathrm{t})-(\mathrm{t}-1))$ and prior to the divorce, which is 27 percent of their time (t-1) wealth. Unlike married couples that divorce, separated individuals have wealth increases during the wave in which they divorce and the wave in which they are divorced.

\footnotetext{
${ }^{8}$ We analyze characteristics of this sample restricted to be in four consecutive waves and find no statistically significant differences in average age, education, number of children, mean and median wealth or earnings. Although the differences are not statistically different, the sample in four consecutive waves has slightly higher wealth and earnings.
} 
Wealth change is positive for all groups that change marital status, after the change. In fact, the wealth change from $t+1$ to $t+2$ for married to divorced, divorced to married and married to married is similar and is between $\$ 22,000$ and $\$ 25,000$ but represents a larger percentage of wealth for divorced individuals who went from married to divorced. The wealth change experience of married individuals who are widowed between time ( $\mathrm{t})$ and $(\mathrm{t}+1)$ is much different than those who divorced. There is no significant wealth loss in the years before the widowing occurred, the widowing results in a wealth decline of $\$ 11,602$ over two years or about 5 percent of their married (prewidowed) wealth at time (t).

Divorced individuals that remarry accumulate assets while divorced (change (t-1) to $(\mathrm{t})$ is $\$ 35,565)$ at a higher level and rate than those who remain divorced $(\$ 11,019)$. Assets enter the household with marriage: wealth levels increase $\$ 64,789$ between waves that individuals go from divorced to married and then level back to levels and rates similar to those individuals who remain married. Widow and other singles (never married and partners) that marry also show substantial increases in wealth over the waves in which they get married and then a smaller increase in (in level and rate) the following waves in which they are married.

In sum, divorce is associated with wealth loss and the loss in wealth begins before the divorce occurs and wealth recovery in the form of increased savings after the divorce. In contrast, a widowing is associated with much a smaller magnitude of wealth loss. Remarriage and marriage (for never married) is associated with increases in wealth at the time of remarriage consistent with the addition of an individual bringing wealth into the household followed by future wealth increases of lower levels. 


\section{Empirical models of the change in the change in wealth}

Demographic controls, measure of lifetime and current earnings and other rich measures of characteristics accounted for all of the differences in wealth change by marital status among men (exception is partnered men) and some of the difference among women for samples of individuals that did not change marital status. If there is remaining unobserved heterogeneity correlated with marital status then the marginal effects of marital status on wealth change will be biased. We eliminate unobserved heterogeneity fixed over time (e.g. prudence) and measure the effect of marital status and changes in income growth with additional controls for age and year by estimating models of the change in wealth change. We estimate wealth change for individuals that change marital status, before and after the marital status change so measured wealth change is not primarily the result of individuals entering or leaving the household. That is, we use change in wealth change $[(\mathrm{t}+2)-(\mathrm{t}+1)]-[(\mathrm{t})-(\mathrm{t}-1)]$ and the change $((\mathrm{t}+1)-(\mathrm{t}))$ is the wave in which marital status changed and is omitted from the calculation.

Our model of the change in wealth change, for a sample of respondents that are present in 4 consecutive waves, includes all possible marital statuses (excluded is married, no change over time), change in the change in income over this same time period, age, sex and year indicators. ${ }^{9}$ Estimation results are given in Table 7 for all respondents and separately for males and females. The top and bottom 2 percent of the dependent variable (change in wealth change) is trimmed. If there is no change in savings behavior, we would expect the change in the change to be small. The mean

\footnotetext{
${ }^{9}$ We include all respondents from birth cohorts 1947 or earlier. Restricting the sample to respondents in the 1931-1941 and 1942-1947 cohorts as we do in the model with results shown in Tables 4 and 5 does not change our findings.
} 
dependent variable is $\$ 4,188$. We discuss the findings noting that the standard errors around most estimates are large so few statistically differences are found.

Consistent with our earlier findings from models of wealth change on a sample of individuals that do not change marital status, the magnitude of effect of marital status on the change in wealth change among individuals that remain divorced, widowed or single over the four waves is small and not different than for individuals that remain married. For example the change in wealth change is $\$ 912$ less among divorced individuals compared to married individuals and $\$ 3,266$ less for widows compared to married individuals (Table 7). The difference in the change in wealth change between widows and married individuals decrease from the mean difference (Table 6a) once age controls are added. Among women, there is no difference in the change in wealth change of women that stay divorced, widowed or other single women over the four waves (partnered or never married) compared to married women that remain married.

The marginal effects on marital status changes from married or separated to divorced or widowed are positive suggesting transition to a not married state is leading to higher savings relative to the change in savings of married couples. As we saw in Table 6a, the large positive change in wealth change is due to dissaving that occurs in the waves before the wave in which the divorce occurs and the 'recovery' of savings in the divorced state. The inclusion of the change in income change does reduce the magnitude from those reported in Table 6a. Individuals that divorce from a married state have a change in wealth change that is $\$ 46,858$ higher than individuals that remain married. The difference in the change in wealth change between married individuals that divorce and those that remain married is decreased by $\$ 15,270$ from the mean difference $(\$ 62,128$ in Table $6 a)$ 
once controls are added. This estimate is lower for men $(\$ 41,494)$ than women $(\$ 50,478)$. Married individuals that are widowed have a slightly higher change in savings compared to individuals that remain married $(\$ 3,494)$. Widowed men have a small decline in savings and women a small increase relative to men and women that remain married.

Divorced individuals that remarry have a change in savings that is less $(\$-17,606)$ than individuals that remain married. Widowed men and women that marry have a change in wealth change that is more $(\$ 31,907)$ than individuals that remain married. The estimates are imprecisely measured and the inclusion of change in income change and age does not change the magnitude of the difference relative to married couples reported in Table 6a. The effects are different for men and women. For divorced and widowed women, remarriage leads to a higher change in wealth change than married women while for men it leads to a lower change.

Change in savings is declining with age slowly (\$-539) but more rapidly for men (\$-712) than women (\$-444). Savings increases with the change in income growth. For example, a $\$ 1,000$ increase in income growth (change in change in income) increases the change in wealth change by $\$ 208$ (\$241 and \$191 for men and women respectively).

We interpret these findings cautiously. Model estimates of the effects of marital status on change in wealth change are imprecisely measured. Moreover, the estimates on individuals that change marital status are based on short-term changes - changes in savings behavior immediately before and after a marital status event and not reflecting long-term savings behavior. Indeed we find no difference in the change in wealth change between individuals that remain divorced, widowed or single and married over the four waves of data. Finally, throughout this analysis we measure wealth change and not active 
savings. That is, wealth change will include capital gains or losses and other transfers into the household through mechanisms such as pension and inheritance but not through the marital transition itself.

\section{Conclusion}

By comparing wealth levels and lifetime earnings at age 55 of married and remarried individuals by whether they go on to divorce over the next 14 years or not, we found patterns consistent with the role of both selection and wealth loss due to marital dissolution in explaining why married individuals around age 55 have higher wealth than not married individuals. Among individuals with a stable marital status over time, we find the higher savings of couples compared to not married men (except partners) is accounted for by observable differences in economic status, pensions and mortality risk. Observable differences account for between a third and one-half of the mean savings differences between married and divorced, widowed and partnered women and all of the difference between couples and never married women. Estimates from models that control for fixed and unobserved heterogeneity by modeling the change in wealth change reveal no difference in the change in wealth change for men and women that are not married consistently over four waves compared to men and women married consistently over four consecutive waves. There is wealth change associated with changes in marital status. Divorce is associated with wealth loss beginning while married - between four and two years before the divorce occurs- substantially more wealth loss over the two years that the individual transitions from married to divorced, and wealth recovery in the form of increased savings after the divorce. Remarriage is associated with increases in 
wealth at the time of marriage consistent with the addition of an individual bringing wealth into the household and followed by future wealth increases at rates similar to those who do not change marital status. Divorce at older ages is costly and remarriage is wealth enhancing and people appear to respond to marital status changes by changing their savings behavior. 


\section{References}

Cherlin, A. 1992. Marriage, Divorce and Remarriage. Cambridge, MA: Harvard University Press.

Haider, Steven and Gary Solon. 2000. Non-Response Bias in the HRS Social Security Files. RAND Working Paper DRU-2254-NIA, February.

Korenman, Sanders and David Neumark. 1991. Does Marriage Really Make Men More Productive? The Journal of Human Resources 26(2): 282-307.

Lillard, Lee and Yoram Weiss. 1996. Uncertain Health and Survival: Effect on End-ofLife Consumption. Journal of Business and Economic Statistics 15(2): 254-68.

Loughran, David and Julie Zissimopoulos. 2009. Why Wait? The Effect of Marriage and Childbearing on the Wage Growth of Men and Women. The Journal of Human Resources 44(2): 326-349.

Lundberg, Shelly and Elaina Rose. 2002. The Effects of Sons and Daughters on Men's Labor Supply and Wages. Review of Economics and Statistics 84(2): 251-68.

Lupton, Joseph and James Smith 200). 'Marriage, Assets and Savings', 129-52 in Shoshana Grossbard-Shechtman (ed.) Marriage and the Economy: Theory and Evidence from Advanced Industrial Societies. New York and Cambridge: Cambridge University Press.

Mincer, Jacob. 1978. Family Migration Decisions. The Journal of Political Economy 86(5): 749-773.

Waite, Linda. 1995. Does Marriage Matter? Demography 32(4): 483-507.

Zagorsky, Jay. 2005. Marriage and divorce's impact on wealth. Journal of Sociology 41(4): 406-424. 
Table 1. Distribution of Marital Status in 1992 and Changes 1992-2006

\begin{tabular}{lrr}
\hline 1992 Marital Status and Any Change 1992-2006: & No. Obs. & Percent \\
\hline Married in 1992 \& no change & 7,411 & 70.0 \\
Married in 1992 \& divorced & 407 & 3.8 \\
Married in 1992 \& widowed & 1,082 & 10.2 \\
Divorced in 1992 \& no change & 962 & 9.1 \\
Divorced in 1992 \& remarried & 106 & 1.0 \\
Widowed in 1992 \& no change & 583 & 5.5 \\
Widowed in 1992 \& remarried & 34 & 0.3 \\
\hline All & 10,585 & 100.0 \\
\hline
\end{tabular}

Source: HRS 1992-2006

Notes: Sample birth cohort 1931-1941 in 1992 (HRS wave 1). Excludes 47 observations with unknown marital status. 
Table 2. Wealth, Lifetime and Current Earnings in 1992 by Marital Status in 1992 and Changes 1992-2006

\begin{tabular}{lrrrrrr} 
& N & Median & \multicolumn{1}{c}{ Mean } & Ratio \\
\cline { 3 - 6 } & & Wealth & Wealth & LTE & Earnings & Wealth/LTE \\
\hline Married in 1992 \& no change & 5,472 & 173,457 & 363,814 & $1,241,020$ & 57,201 & 0.293 \\
Married in 1992 \& divorced & 204 & 99,919 & 278,365 & $1,026,509$ & 60,821 & 0.271 \\
Married in 1992 \& widowed & 760 & 121,618 & 254,362 & 923,538 & 37,259 & 0.275 \\
Remarried in 1992 \& no change & 1939 & 125,311 & 281,843 & $1,346,968$ & 57,668 & 0.209 \\
Remarried in 1992 \& divorced & 203 & 85,080 & 232,421 & $1,215,924$ & 46,496 & 0.191 \\
Remarried in 1992 \& ever widowed & 322 & 98,271 & 201,530 & $1,021,238$ & 35,652 & 0.197 \\
Divorced in 1992 \& no change & 962 & 33,175 & 116,572 & 636,788 & 24,444 & 0.183 \\
Divorced in 1992 \& ever remarried & 106 & 105,525 & 188,366 & 888,625 & 42,503 & 0.212 \\
Widowed in 1992 \& no change & 583 & 47,684 & 125,835 & 403,610 & 14,904 & 0.312 \\
Widowed in 1992 \& ever remarried & 34 & 129,137 & 199,769 & 521,556 & 26,421 & 0.383 \\
\hline All & 10585 & 129,928 & 293,975 & $1,127,296$ & 49,511 & 0.261 \\
\hline
\end{tabular}

Source: HRS 1992-2006

Notes: Sample birth cohort 1931-1941 in 1992 (HRS wave 1). Excludes 47 observations with unknown marital status. Wealth reported in $\$ 2006$. LTE is lifetime earnings. 
Table 3. Wealth Change Over 2 Years Among Individuals with No Change in Marital Status

\begin{tabular}{lrrrrr} 
& & \multicolumn{3}{c}{ Mean } & \\
\cline { 2 - 5 } & $\mathrm{N}$ & $(\mathrm{t})$ & $(\mathrm{t}+1)$ & $\Delta=(\mathrm{t}+1)-(\mathrm{t})$ & $\begin{array}{r}\Delta \text { as \% of } \\
\text { wealth at }(\mathrm{t})\end{array}$ \\
\cline { 2 - 5 } Married & 51,444 & 349,951 & 372,545 & 22,595 & 6.5 \\
Remarried & 17,576 & 285,050 & 304,423 & 19,373 & 6.8 \\
Divorced & 8,321 & 136,889 & 149,342 & 12,453 & 9.1 \\
Widowed & 19,358 & 161,955 & 167,234 & 5,278 & 3.3 \\
Never Married & 2,928 & 155,061 & 166,029 & 10,968 & 7.1 \\
Partnered & 2,315 & 206,856 & 212,337 & 5,480 & 2.6 \\
\hline All & 101,942 & 276,824 & 294,024 & 17,200 & 6.2 \\
\hline
\end{tabular}

Source: HRS 1992-2006

Notes: Sample individuals not changing marital status over two waves of data. Wealth in \$2006. 
Table 4. Model Results for Wealth Change Among Individuals Not Changing Marital Status

\begin{tabular}{lrlrl} 
& \multicolumn{4}{c}{ Wealth Change } \\
\cline { 2 - 5 } Variable & \multicolumn{4}{c}{ Marginal effects } \\
\cline { 2 - 5 } [Married] & $-4,432$ & $* *$ & $-3,240$ & \\
Remarried & $-9,792$ & $* *$ & $-5,146 \quad *$ \\
Divorced & $-15,886$ & $* *$ & $-7,922$ & $* *$ \\
Widowed & $-8,513$ & $*$ & $-5,977$ & \\
Never Married & $-18,354$ & $* *$ & $-13,067$ & $* *$ \\
Partnered & 1,464 & 358 & \\
Male & $-12,887$ & $-8,432$ & \\
Black & $-9,549$ & $-4,218$ & \\
Other non-white & yes & yes & \\
\hline Age, year & no & yes & \\
Income + other controls & 19,949 & 19,949 & \\
Mean Dep. & 71,128 & 71,128 \\
Observations & &
\end{tabular}

Source: HRS 1992-2006.

Notes: Sample is individuals not changing marital status in consecutive waves, excluding unknown married (339 obs), birth cohorts 1931-1947. Wealth change trimmed top \& bottom $2 \%$. 
Table 5. Model Results for Wealth Change Among Individuals Not Changing Marital Status By Sex

Wealth Change

\begin{tabular}{|c|c|c|c|c|c|c|c|}
\hline \multicolumn{4}{|c|}{ Men } & \multicolumn{4}{|c|}{ Women } \\
\hline \multicolumn{4}{|c|}{ Marginal effects } & \multicolumn{4}{|c|}{ Marginal effects } \\
\hline Model (1) & & Model (2) & & Model (1) & & Model (2) & \\
\hline$-4,012$ & & $-3,245$ & & $-4,806$ & * & $-3,054$ & \\
\hline$-5,136$ & & -368 & & $-12,397$ & $* *$ & $-7,390$ & * \\
\hline$-8,227$ & & $-4,133$ & & $-17,948$ & $* *$ & $-9,172$ & $* *$ \\
\hline$-8,128$ & & $-7,400$ & & $-9,174$ & & $-5,740$ & \\
\hline$-18,825$ & $* *$ & $-13,355$ & $*$ & $-17,824$ & $* *$ & $-12,591$ & $*$ \\
\hline$-15,232$ & & $-10,134$ & & $-11,210$ & & $-7,252$ & \\
\hline$-9,968$ & & $-3,748$ & & $-9,087$ & & $-4,452$ & \\
\hline yes & & yes & & yes & & yes & \\
\hline no & & yes & & no & & yes & \\
\hline 21,986 & & 21,986 & & 18,312 & & 18,312 & \\
\hline 31,685 & & 31,685 & & 39,443 & & 39,443 & \\
\hline
\end{tabular}

[Married]

Remarried

Divorced

Widowed

Never Married

Partnered

Black

Other non-white

Age, year

Income + controls

Mean Dep.

Observations

Source: HRS 1992-2006.

Notes: Sample is individuals not changing marital status in consecutive waves, excluding unknown married (339 obs), birth cohorts 1931-1947. Wealth change trimmed top \& bottom 2\% 
Table 6a. Wealth Change Among Individuals Changing and Not Changing Marital Status

\begin{tabular}{|c|c|c|c|c|c|c|c|c|c|c|}
\hline \multirow[b]{2}{*}{$\begin{array}{l}\text { Mstat at } \\
\mathrm{t}-1 \& \mathrm{t}\end{array}$} & \multirow[b]{2}{*}{$\begin{array}{l}\text { Mstat at } \\
\mathrm{t}+1 \& \mathrm{t}+2\end{array}$} & \multicolumn{4}{|c|}{$\begin{array}{l}\text { Mstat Change } \\
\text { between } t \text { and } t+1\end{array}$} & Mstat & $\Delta \mathrm{t}$ & $\Delta(t+1)$ & & \multirow{2}{*}{$\begin{array}{c}\Delta(\mathrm{t}+2)-\Delta \mathrm{t} \\
{[(\mathrm{t}+2)-} \\
(\mathrm{t}+1)]- \\
{[(\mathrm{t})-(\mathrm{t}-1)]}\end{array}$} \\
\hline & & $\mathrm{N}$ & $\mathrm{t}-1$ & $\mathrm{t}$ & $\mathrm{t}+1$ & $t+2$ & $(\mathrm{t})-(\mathrm{t}-1)$ & $(t+1)-(t)$ & $\begin{array}{c}(\mathrm{t}+2)- \\
(\mathrm{t}+1)\end{array}$ & \\
\hline Married & Divorced & 95 & 291,125 & 251,206 & 118,428 & 140,638 & $-39,918$ & $-132,779$ & 22,210 & 62,128 \\
\hline Separated & Divorced & 60 & 160,531 & 117,673 & 161,568 & 171,434 & $-42,858$ & 43,895 & 9,866 & 52,724 \\
\hline Married & Widowed & 1,518 & 241,539 & 240,363 & 228,761 & 229,410 & $-1,176$ & $-11,602$ & 649 & 1,826 \\
\hline Divorced & Married & 67 & 154,940 & 190,505 & 255,293 & 278,591 & 35,565 & 64,789 & 23,298 & $-12,267$ \\
\hline Widowed & Married & 65 & 288,861 & 312,180 & 447,799 & 508,835 & 23,318 & 135,619 & 61,036 & 37,718 \\
\hline Single & Married & 76 & 264,758 & 310,712 & 384,774 & 398,305 & 45,954 & 74,061 & 13,531 & $-32,423$ \\
\hline Married & Married & 38,129 & 334,700 & 354,144 & 374,555 & 399,985 & 19,444 & 20,411 & 25,430 & 5,986 \\
\hline Divorced & Divorced & 3,823 & 135,639 & 146,657 & 152,885 & 169,882 & 11,019 & 6,227 & 16,997 & 5,978 \\
\hline Widowed & Widowed & 8,276 & 170,562 & 174,701 & 171,482 & 170,578 & 4,140 & $-3,219$ & -904 & $-5,044$ \\
\hline Single & Single & 2,298 & 169,071 & 182,858 & 195,303 & 212,353 & 13,786 & 12,445 & 17,050 & 3,264 \\
\hline
\end{tabular}

Source: HRS 1992-2006

Notes: Sample is individuals changing marital status and in four consecutive waves of data.

Wealth in $\$ 2006$. Single is never married and partnered. Trimmed top and bottom $2 \%$ of $\Delta$.

Table $6 b$.

\begin{tabular}{llrrrr} 
& & \multicolumn{4}{c}{ Between wave change as \% of prior wave wealth } \\
\cline { 4 - 6 } Mstat at & Mstat at & & & & \\
$\mathrm{t}-1 \& \mathrm{t}$ & $\mathrm{t}+1 \& \mathrm{t}+2$ & $\mathrm{~N}$ & {$[(\mathrm{t})-(\mathrm{t}-1) / \mathrm{t}-1]^{*} 100$} & {$[(\mathrm{t}+1)-(\mathrm{t}) / \mathrm{t}]^{*} 100$} & {$[(\mathrm{t}+2)-(\mathrm{t}+1) / \mathrm{t}+1]^{*} 100$} \\
\hline Married & Divorced & 95 & -13.7 & -52.9 & 18.8 \\
Separated & Divorced & 60 & -26.7 & 37.3 & 6.1 \\
Married & Widowed & 1,518 & -0.5 & -4.8 & 0.3 \\
Divorced & Married & 67 & 23.0 & 34.0 & 9.1 \\
Widowed & Married & 65 & 8.1 & 43.4 & 13.6 \\
Single & Married & 76 & 17.4 & 23.8 & 3.5 \\
Married & Married & 38,129 & 5.8 & 5.8 & 6.8 \\
Divorced & Divorced & 3,823 & 8.1 & 4.2 & 11.1 \\
Widowed & Widowed & 8,276 & 2.4 & -1.8 & -0.5 \\
Single & Single & 2,298 & 8.2 & 6.8 & 8.7 \\
\hline
\end{tabular}

Source: HRS 1992-2006

Notes: Sample is individuals changing marital status and in four consecutive waves of data.

Wealth in \$2006. Single is never married and partnered. 
Table 7. Model of Change in Wealth Change Before $(\mathrm{t})-(\mathrm{t}-1)$ and After $(\mathrm{t}+2)-(\mathrm{t}+1)$ Marital Status Change

\begin{tabular}{|c|c|c|c|c|c|c|c|}
\hline & & \multicolumn{6}{|c|}{ Total Wealth $((\mathrm{t}+2)-(\mathrm{t}+1))-((\mathrm{t})-(\mathrm{t}-1))$} \\
\hline & & \multicolumn{6}{|c|}{ Marginal Effects } \\
\hline & & All & stderr & Male & stderr & Female & stderr \\
\hline \multicolumn{2}{|l|}{ Intercept } & 29,660 & 9,686 & 42,263 & 17,152 & 23,008 & 11,725 \\
\hline $\begin{array}{l}\text { Marital Status in } \\
\text { (t) \& (t-1): } \\
\text { [Married] }\end{array}$ & $\begin{array}{l}\text { Marital Status } \\
(\mathrm{t}+2) \&(\mathrm{t}+1) \text { : } \\
{[\text { Married] }}\end{array}$ & & & & & & \\
\hline Divorced & Divorced & -912 & 4,981 & $-4,415$ & 9,432 & 1,098 & 5,806 \\
\hline Widowed & Widowed & $-3,266$ & 4,040 & $-4,175$ & 9,795 & $-3,049$ & 4,598 \\
\hline Other Single & Other Single & $-1,963$ & 6,270 & $-1,214$ & 9,988 & $-2,807$ & 8,051 \\
\hline Married & Divorced & 46,858 & 29,986 & 41,494 & 48,045 & 50,478 & 38,265 \\
\hline Separated & Divorced & 46,828 & 37,706 & 72,508 & 64,724 & 31,900 & 46,002 \\
\hline Married & Widowed & 3,494 & 7,772 & $-2,844$ & 15,933 & 5,058 & 8,760 \\
\hline Divorced & Married & $-17,606$ & 35,677 & $-54,418$ & 48,631 & 33,944 & 53,570 \\
\hline Widowed & Married & 31,907 & 36,224 & $-9,202$ & 56,381 & 65,841 & 47,262 \\
\hline Other Single & Married & $-40,975$ & 33,526 & $-53,532$ & 49,289 & $-26,563$ & 46,017 \\
\hline \multicolumn{2}{|l|}{ Age } & -539 & 145 & -712 & 254 & -444 & 181 \\
\hline \multicolumn{2}{|c|}{ Male } & 730 & 2,641 & & & & \\
\hline \multicolumn{2}{|c|}{ Income change $((\mathrm{t}+2)-(\mathrm{t}+1))-((\mathrm{t})-(\mathrm{t}-1))$} & 0.208 & 0.011 & 0.241 & 0.020 & 0.191 & 0.014 \\
\hline \multicolumn{8}{|c|}{ Four consecutive data waves are: } \\
\hline \multicolumn{2}{|c|}{ 1992/93, 1994/95, 1996, and 1998} & 7,621 & 3,724 & 9,767 & 6,036 & 6,147 & 4,716 \\
\hline \multicolumn{2}{|c|}{$1994 / 1995,1996,1998$, and 2000} & 27,184 & 4,300 & 28,725 & 6,773 & 25,982 & 5,570 \\
\hline \multicolumn{2}{|c|}{$1996,1998,2000$ and 2002} & $-16,883$ & 3,866 & $-21,953$ & 6,273 & $-13,277$ & 4,889 \\
\hline \multicolumn{2}{|c|}{ 2000, 2002, 2004 and 2006} & 34,785 & 3,745 & 39,111 & 6,084 & 31,771 & 4,732 \\
\hline \multicolumn{2}{|c|}{ Mean Dependent } & 4,188 & & 5,774 & & 3,058 & \\
\hline \multicolumn{2}{|l|}{ Observations } & 54,407 & & 22,629 & & 31778 & \\
\hline
\end{tabular}

Source: HRS 1992-2006.

Notes: Sample is individuals in four consecutive waves, excluding unknown married (339 obs), birth 1947 and earlier. Dependent variable, 'change in wealth change' excludes wealth changes between the waves in which the marital transitions occurs ( $t$ and $t+1$ ) and values in the top \& bottom $2 \%$ are trimmed. Age is measured at time $(\mathrm{t})$. 
Appendix Table A: Model Results for Wealth Change Among Individuals Not Changing Marital Status

\begin{tabular}{|c|c|c|c|c|c|c|}
\hline & \multicolumn{2}{|c|}{ All } & \multicolumn{2}{|l|}{ Males } & \multicolumn{2}{|c|}{ Females } \\
\hline & $\mathrm{df} / \mathrm{dx}$ & stdder & $\mathrm{df} / \mathrm{dx}$ & stdder & $\mathrm{df} / \mathrm{dx}$ & stdder \\
\hline Intercept & $-57,162$ & 33,749 & $-71,127$ & 50,861 & $-57,368$ & 46,266 \\
\hline Male & 358 & 1,442 & & & & \\
\hline Remarried & $-3,240$ & 1,795 & $-3,245$ & 2,636 & $-3,054$ & 2,473 \\
\hline Divorced & $-5,146$ & 2,520 & -368 & 4,430 & $-7,390$ & 3,101 \\
\hline Widowed & $-7,923$ & 2,680 & $-4,133$ & 6,510 & $-9,172$ & 2,995 \\
\hline Never Married & $-5,977$ & 4,758 & $-7,400$ & 8,007 & $-5,740$ & 5,886 \\
\hline Partnered & $-13,067$ & 4,231 & $-13,355$ & 6,231 & $-12,591$ & 5,790 \\
\hline Age & 2,486 & 1,099 & 2,730 & 1,651 & 2,608 & 1,499 \\
\hline Age-squared & -25 & 9 & -27 & 14 & -27 & 13 \\
\hline Less high school & $-4,773$ & 1,873 & $-4,953$ & 2,953 & $-4,794$ & 2,420 \\
\hline Some college & 4,317 & 1,913 & 5,631 & 2,943 & 3,449 & 2,514 \\
\hline College & 20,664 & 2,063 & 19,778 & 3,147 & 22,027 & 2,735 \\
\hline Black & $-8,432$ & 1,995 & $-10,134$ & 3,271 & $-7,252$ & 2,508 \\
\hline Other non-white & $-4,218$ & 3,544 & $-3,748$ & 5,668 & $-4,452$ & 4,523 \\
\hline No kids & 1,237 & 4,558 & 4,873 & 7,086 & $-1,962$ & 6,058 \\
\hline 4 or more kids & $-1,669$ & 1,522 & $-2,972$ & 2,373 & -761 & 1,978 \\
\hline Mortality risk: dev. from lifetable: & & & & & & \\
\hline Living 10-19 more yrs & 76 & 30 & 106 & 47 & 58 & 39 \\
\hline Living 20-29 more yrs & 60 & 51 & 47 & 90 & 64 & 61 \\
\hline Least risk averse & 1,504 & 2,264 & 3,891 & 3,510 & -629 & 2,959 \\
\hline Third most risk averse & 1,022 & 2,409 & 2,499 & 3,756 & -94 & 3,132 \\
\hline Second most risk averse & 3,834 & 2,269 & 3,311 & 3,516 & 4,273 & 2,964 \\
\hline 5-10yr financial planning horizon & 215 & 1,652 & 835 & 2,555 & -47 & 2,163 \\
\hline $10+\mathrm{yr}$ financial planning horizon & 2,538 & 2,545 & 2,259 & 3,933 & 2,931 & 3,336 \\
\hline HH earnings quintile 2 & -747 & 2,165 & $-1,021$ & 3,367 & -532 & 2,856 \\
\hline HH earnings quintile 3 & $-4,547$ & 2,291 & $-1,779$ & 3,521 & $-5,581$ & 2,978 \\
\hline HH earnings quintile 4 & $-6,946$ & 2,395 & $-3,667$ & 3,674 & $-6,874$ & 3,150 \\
\hline HH earnings quintile 5 & 10,518 & 2,523 & 7,312 & 3,888 & 10,547 & 3,330 \\
\hline PDV lifetime earnings quintile 2 & 4,780 & 7,788 & 9,979 & 14,776 & 4,705 & 9,079 \\
\hline PDV lifetime earnings quintile 3 & 4,596 & 7,823 & 6,202 & 14,809 & 2,691 & 9,137 \\
\hline PDV lifetime earnings quintile 4 & 3,608 & 7,857 & 8,357 & 14,836 & 1,711 & 9,188 \\
\hline PDV lifetime earnings quintile 5 & 14,103 & 7,915 & 19,372 & 14,886 & 12,075 & 9,293 \\
\hline Household has DB pension & 8,708 & 2,215 & 9,243 & 3,391 & 8,522 & 2,928 \\
\hline Household has DC pension & 10,758 & 2,247 & 12,496 & 3,441 & 9,629 & 2,966 \\
\hline Household has DB\&DC pension & 28,930 & 2,579 & 30,641 & 3,863 & 27,808 & 3,469 \\
\hline Birth Cohort 1942-1947 & $-3,671$ & 2,592 & $-4,255$ & 3,997 & $-3,165$ & 3,407 \\
\hline 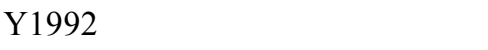 & 5,721 & 2,769 & 6,116 & 4,284 & 5,280 & 3,625 \\
\hline Y1994 & $-6,385$ & 2,725 & $-6,696$ & 4,228 & $-6,114$ & 3,557 \\
\hline Y1996 & 16,649 & 2,687 & 20,649 & 4,161 & 13,392 & 3,509 \\
\hline Y1998 & 15,586 & 2,525 & 17,904 & 3,921 & 13,482 & 3,295 \\
\hline Y2002 & 15,402 & 2,554 & 17,277 & 3,978 & 13,990 & 3,321 \\
\hline Y2004 & 24,116 & 2,643 & 26,741 & 4,137 & 22,256 & 3,425 \\
\hline $\mathrm{N}$ & 71,128 & & 31,685 & & 39,443 & \\
\hline
\end{tabular}

Source: HRS 1992-2006.

Notes: Sample is individuals not changing marital status in consecutive waves, excluding unknown married (339 obs), WBB or HRS cohort. Wealth change trimmed top \& bottom $2 \%$. 
Appendix Table B. Means of model covariates from Tables 4 and 5

\begin{tabular}{lrrr} 
& All & Males & Females \\
\hline Male & 0.445 & 1.000 & 0.000 \\
Remarried & 0.231 & 0.268 & 0.201 \\
Divorced & 0.095 & 0.068 & 0.117 \\
Widowed & 0.086 & 0.029 & 0.132 \\
Never Married & 0.029 & 0.026 & 0.031 \\
Partnered & 0.029 & 0.032 & 0.026 \\
Age & 59.634 & 59.526 & 59.721 \\
Less high school & 0.239 & 0.226 & 0.249 \\
Some college & 0.200 & 0.203 & 0.197 \\
College & 0.182 & 0.190 & 0.175 \\
Black & 0.155 & 0.133 & 0.173 \\
Other non-white & 0.040 & 0.038 & 0.043 \\
No kids & 0.059 & 0.064 & 0.055 \\
4 or more kids & 0.393 & 0.387 & 0.397 \\
Mortality risk: dev. from lifetable: & & & \\
Living 10-19 more yrs & -4.827 & -2.979 & -6.311 \\
Living 20-29 more yrs & -3.630 & -2.675 & -4.397 \\
Least risk averse & 0.111 & 0.112 & 0.110 \\
Third most risk averse & 0.095 & 0.094 & 0.096 \\
Second most risk averse & 0.110 & 0.111 & 0.110 \\
5-10yr financial plan horizon & 0.273 & 0.287 & 0.261 \\
10+ yr financial plan horizon & 0.086 & 0.088 & 0.085 \\
Current earnings & 30,059 & 31,804 & 28,669 \\
PDV lifetime earnings & 813,044 & 893,356 & 747,993 \\
Household has DB pension & 0.149 & 0.153 & 0.146 \\
Household has DC pension & 0.137 & 0.141 & 0.134 \\
Household has DB\&DC pension & 0.112 & 0.123 & 0.104 \\
Birth Cohort 1942-1947 & 0.115 & 0.120 & 0.112 \\
Y1992 & 0.146 & 0.150 & 0.144 \\
Y1994 & 0.138 & 0.139 & 0.137 \\
Y1996 & 0.132 & 0.132 & 0.131 \\
Y1998 & 0.155 & 0.156 & 0.153 \\
Y2002 & 0.145 & 0.143 & 0.147 \\
Y2004 & 0.138 & 0.133 & 0.141 \\
\hline Number of Observations & 71,128 & 31,685 & 39,443 \\
\hline Source HRS 1992-2006. & &
\end{tabular}

Source: HRS 1992-2006.

Notes: Sample is individuals not changing marital status in consecutive waves, excluding unknown married (339 obs), birth cohorts 1931-1947. Earnings in \$2006 